\title{
An analysis of semiotic and mimetic processes in Australopithecus afarensis
}

\begin{abstract}
Jenny Michlich
The underlying semiotic structures of communicative processes involving spoken language vocalizations and gesturing are analyzed in order to contribute to the interdisciplinary discussion on human cognitive-semiotic evolution. Peircean semiotics and mimesis theory are used as tools in the analysis of evidence from comparative neuroscience and primatology. Based on this, I propose the presence of indexical, iconic and possibly even (proto)symbolic communication in the cultures occupied by Australopithecus afarensis, preceding the evolution of the first species in our genus. The discussion shows the potentials of a cognitive semiotics to integrate concepts and methods from the Natural Sciences and the Humanities.
\end{abstract}

Key words: Peircean semiotics, mimesis, gestures, vocalizations, Broca's area

\section{Introduction}

What is a sign and how has the modern mind developed to use and interpret signs? When did sign use develop in the hominin line since the split between the last common ancestor of the genus Pan and modern Homo sapiens between 6.3Ma and 4Ma (Patterson, 2006). This paper addresses these questions through the use of Peircean semiotics and mimesis theory (Donald, 1991, 2013; Zlatev, 2005, 2008). This theoretical model can then be applied to the archaeological record in order to interpret the development of semiotic thought in $A$. afarensis. An additional discussion of Broca's area in both non-human primates and modern humans is provided, serving as a comparative framework for aspects of vocalization and language production. Further, I explore the archaeological record and a comparative analysis of cranial reorganization of $A$. afarensis, which provides evidence for the presence of stone tool technology, pedagogy and intentional communication in that species. Finally, I consider the implications of this analysis for further studies involving extralinguistic properties of human communication, as well as the role of somatosensory integration as it relates to the theory of bodily mimesis.

\section{Theoretical background}

\subsection{Peircean semiotics}

Within the context of Peircean semiotics, signs are defined as relational structures consisting of Representamen, Object, and Interpretant, in relation to the universal categories of Firstness, Secondness, and Thirdness (Innis, 1985; Nöth, 1990; Sonesson, 2013). These categories can be interpreted as different modes of being, or less controversially as forms of semiosis (meaning making). In line with cognitive semiotics (Sonesson, 2013; Zlatev, 2015), these categories can be understood in terms of sensory and cognitive processes and representations. Firstness is experienced as primary sensory information and does not require an interpretive or reactive physiological or cognitive response. There is no oppositional form 
in Firstness and it does not imply a relation to any other object or relation. Secondness is a product of a response to Firstness. Thirdness is a "law" or "habit", reflecting the awareness of the relationship between Secondness and Firstness. This formulation shows that the three categories form an interdependent hierarchy, with semiosis increasing in complexity from Firstness, to Secondness, to Thirdness. Table 1 presents definitions of these concepts in the work of Peirce and some interpretations of these in the recent literature (Sonensson, 2013; Sáenz-Ludlow \& Kadunz, 2016).

Table 1. The universal categories of Peircean semiotics

\begin{tabular}{|l|l|l|}
\hline Category & $\begin{array}{l}\text { Technical definition according to } \\
\text { Charles Pierce }\end{array}$ & $\begin{array}{l}\text { Interpretations of original Definition } \\
\text { "Firstness }\end{array}$ \\
\begin{tabular}{|l} 
"Firstness is the mode of being of \\
that which is such as it is, positively \\
and without any reference to anything \\
else" (1904, CP 8:328).
\end{tabular} & $\begin{array}{l}\text { A. "something there" (Sonensson, 2013, p. 312) } \\
\text { B. "the first level of meaning derived from } \\
\text { bodily and sensory processes" (Sáenz-Ludlow \& } \\
\text { Kadunz, 2016, p. 4) }\end{array}$ \\
\hline Secondness & $\begin{array}{l}\text { "Secondness is the mode of being of } \\
\text { that which is such as it is, with } \\
\text { respect to a second but regardless of } \\
\text { any third" (1904, CP 8:328). }\end{array}$ & $\begin{array}{l}\text { A. "as a reaction to something else" (Sonensson, } \\
\text { 2013, p. 312) } \\
\text { B. "Seconds are experience and the reaction is } \\
\text { causes together with the effect it provokes; but } \\
\text { not yet a reflection on the reaction or the effect" } \\
\text { (Sáenz-Ludlow \& Kadunz, 2016, p. 4). }\end{array}$ \\
\hline $\begin{array}{l}\text { "Thirdness is the mode of being of } \\
\text { that which is such as it is, in bringing } \\
\text { a second and third into relation to } \\
\text { each other" (1904, CP 8:328). }\end{array}$ & $\begin{array}{l}\text { A. "someone observing something in relation to } \\
\text { something else" (Sonensson, 2013, p. 312) } \\
\text { B. "Thirds are experience and reaction together } \\
\text { with the reflection upon that reaction" (Sáenz- } \\
\text { Ludlow \& Kadunz, 2016, p. 4). }\end{array}$ \\
\hline
\end{tabular}

There is a correspondence between the universal categories and the three parts that jointly constitute the sign: Representmen, Object (immediate or dynamical), and the Interpretant (immediate, dynamical, or final). Moving from Firstness to Thirdness the Representamen becomes increasingly "embodied" and differentiated, from Qualisign, to Sinsign, to Legisign (see Table 2). The Representamen provides a quality or point of reference to derive meaning from the Object. The immediate Object is defined by the Representamen, while the dynamical Object is the "thing itself", outside of the sign process (Nöth, 1990). The relationship between Representamen and Object is the ground (Sonesson, 2013), and depending on its type, there are three kinds of signs ideally (actual signs are usually combinations of these grounds). The Icon is a sign where the Representamen resembles its Object. The Index is a sign where the Representamen is in proximity with the Object and the Symbol is a sign where the Representamen is related to the Object in terms of "habit" or convention (see Table 2).

Finally, there are three main types of Interpretants: the immediate which is a "semantic intentioniality" of the unanalyzed potential of a sign, the dynamical which is the experience of the act of interpretation, and lastly the final which is the ultimate interpretation 
of the sign (Innis, 1985). This final aspect of the triad is indicative of the type of cognition produced in semiosis. ${ }^{1}$

Table 2. Relationships between concepts in Peircean semiotics

\begin{tabular}{|l|l|l|l|}
\hline Categories & Representamen & $\begin{array}{l}\text { Ground (Representamen-Object } \\
\text { relation) }\end{array}$ & Interpretant \\
\hline Firstness & $\begin{array}{l}\text { The Qualisign is a } \\
\text { "quality which is a } \\
\text { sign" that cannot act as } \\
\text { a sign without } \\
\text { embodiment (Innis, } \\
\text { 1985, p. 7). }\end{array}$ & $\begin{array}{l}\text { The Icon is "a sign which refers to } \\
\text { the Object that it denotes merely by } \\
\text { virtue of characters of its own, and } \\
\text { which it possesses, just the same, } \\
\text { whether any such Object actually } \\
\text { exists or not." (Innis, 1985, p. 8). }\end{array}$ & $\begin{array}{l}\text { A Rheme is "a sign of } \\
\text { qualitative possibility } \\
\text { that is understood as } \\
\text { representing such and } \\
\text { such a kind of possible } \\
\text { Object" (Innis, 1985, p. } \\
\text { 9). }\end{array}$ \\
\hline Secondness & $\begin{array}{l}\text { The Sinsign is an } \\
\text { "actual existent thing } \\
\text { or event" (Innis, 1985, } \\
\text { p. 7). }\end{array}$ & $\begin{array}{l}\text { The Index is "a sign, which refers to } \\
\text { the Object that it denotes by virtue of } \\
\text { being really affected by that Object" } \\
\text { (Innis, 1985, p. 8). }\end{array}$ & $\begin{array}{l}\text { The Dicent is "a sign of } \\
\text { actual existence" (Innis, } \\
\text { p. 9). }\end{array}$ \\
\hline Thirdness & $\begin{array}{l}\text { The Legisign is a law } \\
\text { that is a sign (Innis, } \\
\text { 1985, p. 7). }\end{array}$ & $\begin{array}{l}\text { The Symbol is "a sign, which refers } \\
\text { to the Object that it denotes by virtue } \\
\text { of a law, usually an association of } \\
\text { general ideas, which operates to } \\
\text { cause the Symbol to be interpreted as } \\
\text { referring to that Object" (Innis, 1985, } \\
\text { p. 8). }\end{array}$ & $\begin{array}{l}\text { The Argument is "a } \\
\text { sign of law" (Innis, } \\
1985, \text { p. 9). }\end{array}$ \\
\hline
\end{tabular}

\subsection{Mimesis theory}

Another semiotic theory, explicitly developed for the purpose of explaining human cognitivesemiotic evolution, employs the concept of mimesis, defined as "the ability to produce conscious, self-initiated, representational acts that are intentional but not linguistic" (Donald, 1991, p. 168). This implies that mimesis is a process that requires both the ability to imagine, and to represent an event with the help of the body, beyond that of simple mimicry or even the cognitive demanding process of imitation. In Donald's original theory, the neurocognitive adaptation of mimesis distinguished the cognition and culture of Homo egraster/erectus (1.8-0.5 MYA) from the "episodic" cognition of the common ancestor to hominins and extant apes, and eventually lead to the evolution of language-based mythic

\footnotetext{
${ }^{1}$ Further subcategorization occurs as these aspects of semiosis interact forming a total of 10 semiotically possible combinations: A Rhematic Iconic Qualisign e.g "feeling of "red", Rhematic Iconic Legisign e.g "diagram apart from its factual individuality," Rhematic Symbol Legisign e.g "a common noun," Argument Symbolic Legisign e.g. "a syllogism," Rhematic Iconic Sinsign e.g. "an individual diagram," Rhematic Indexical Legisign e.g "a demonstrative pronoun," Dicent Symbol Legisign e.g. "an ordinary proposition," Rhematic Indexical Sinsign e.g. "a spontaneous cry," Dicent Indexical Legisign e.g. "a street cry," and Dicent Indexical Sinsign e.g. "a weathercock" (Innis, 1985, p. 19-22).
} 
cultures of modern Homo sapiens (Donald, 1991).

Zlatev (2008) further developed the concept of bodily mimesis, distinguishing between simple forms, within the repertoire of non-human primates, and complex, postmimetic capacities leading to language. The simplest form is proto-mimesis, in which a perceived act is mapped onto one's own body automatically, as in emotional contagion and neonatal imitation. This is very similar to the notion of mimicry. Dyadic mimesis involves "imitation and imaginary re-enactment," but does not imply intentional sign use. It is first in the case of triadic mimesis, realized as declarative pointing and iconic gestures that communicative signs occur, on the basis of indexical and iconic, but not yet symbolic grounds (see Table 2). Symbols, and simple combinations of these appear first in postmimesis 1 (or "protolanguage"), and full language corresponds to post-mimesis 2 where "the act dividing (semi)compositionally into meaningful sub-acts" (Zlatev, 2008, p.142-143), implying the existence of grammar. An integrated approach involving both the framework for bodily mimesis and semiotic capacities in both gesture and vocalization may serve as a model accounting for the continuum from pre-linguistic stages to that of the underlying structures of language (Sonesson, 2018).

After a general introduction to evidence from primatology, these theories will be applied to evidence from the archaeological record to analyze the cognitive semiotic mechanisms in Australopithecus afarensis. The general methodology is based on a review of evidence comparing nonhuman primate cognitive capacities with those of humans, and indirect evidence of the cognitive capacities of A. afarensis based on endocasts.

\section{Empirical evidence from primatology}

\subsection{Primate vocalizations}

Since modern primates and $H$. sapiens share a common ancestor, it is possible to use evidence from primatology concerning cognition, language and anatomy in order to attempt to reconstruct stages in human cognitive-semiotic evolution. However, it is important to note that nonhuman primates have developed their own evolutionary path and should not be considered an "underevolved, prehuman" (Matthews, 2015, p. 13).

Studying nonhuman primates' social interactions in natural settings has demonstrated that primates are capable of certain types of semiotic processes through the use of vocalizations and gesturing. Because primates are also social animals, understanding these vocalizations and gestures by conspecifics would be required in order for cohesion and at least some degree of cooperation to occur (Sapolsky, 2006). This implies a degree of shared meaning or intentionality between members of a specific group of nonhuman primates. While the study of sign-based communication in relation to gesture has yielded results about the semantic content of intraspecies iconic and indexical gesture repertoires (Tomasello, 2008), less is known about the potential for precursors of grammatical and syntactical structures of non-human primate vocalizations (Graham et al., 2018). However, it is noted in several cases in the literature that chimpanzees and bonobos in natural settings do produce vocalizations and alarm calls that are specific to objects present in their environments, and these vocalizations have some structured order or recognizable combination (Crockford \& Boesch, 2005; Clay \& Zuberbühler, 2009).

Semiotic analysis can be applied to the vocalizations of a particular group of African vervet monkeys, Campbell's monkeys (Cercopithecus campbelli), living in the Ivory Coast 
(Ouattara, Lemasson, \& Zuberbühler, 2009a). It is often stated that non-human primate vocalizations are not symbolic (Deacon, 1997), and this is often described as the reason for not using nonhuman primate vocalizations as models for the evolution of human language, in addition to the limitations of the range of vocalizations that nonhuman primates can produce (Ouattara, Lemasson, \& Zuberbühler, 2009a). However, in Campbell's monkeys in West Africa there is some evidence for syntax. Alarm calls may be modified with the "suffix" -oo to signify changes in meaning related to specific predation threats (Peterson, 2017). The krak and hok calls were generally noted to signal the presence of a predator within the given territory, particularly leopards and eagles. These were used either as an indication of physical presence within the given territory or as an indication of auditory cues signaling the presence of either predator (Ouattara, Lemasson, \& Zuberbühler, 2009a). It was also noted in a subsequent study by the same authors that the semantic content of these calls was modified by vocalization order and the degree of repetition with a given call sequence (Schlenker et al., 2014). Given that krak and hok can be modified by a suffix and this modification is also tied to the modification of the meaning of the given call, these vocalizations can be interpreted as indexes in terms of Peircean semiotics. More specifically, krak and hok can be interpreted as Rhematical Indexical Sinsigns (see footnote 1) when produced in response to auditory cues as the call indicates the presence of a predator within the territory without the presence of the actual object of reference, and as Dicent Indexical Sinsigns when visual cueing occurs as the call serves as an indexical reference to the location and presence of a known object. Behavioral changes to males producing such modified vocalizations seemed to suggest that this modification signified a greater territorial threat (Ouattara, Lemasson, \& Zuberbühler, 2009b).

In addition, this population of monkeys also produced the alarm calls boom and wok, which were also produced in combination and sequence with the previously mentioned alarm calls (Ouattara, Lemasson, \& Zuberbühler, 2009a). Boom calls were associated with movements of the group directed by outlaying males within the periphery of the group territory, and these components served as a basis for initiation of alarm calls for this particular group. As noted by the authors, and something that is an important point to consider as we further discuss intentionality in gesture and communication in the next section, that the different calls did have ordered and buildable structure. Because the processes of iconicity, indexicality, and symbolism constitute a chain of semiotic meaning (see Table 2), repetition and situating vocalizations within a social context allows for indexical signs to acquire some degree of conventional meaning, making them protosymbolic. Given that such vocalizations and gesture are embodied within the context of mimesis (see Section 4), such meaningful, intentional interactions without symbolic representation, may allow for types of "proto-language" to potentially emerge. Since this type of behavior is exhibited in Old World Monkeys and that there is also evidence that some Great Apes in natural settings can also communicate via gestures (Tomasello, 2008), this leaves open the possibility of extending a "richer" semiotic interpretation to early hominins.

\subsection{Neuroanatomical evidence}

In order to reach an informed interpretation of the communicative signals of non-human primates, we need to address the issues of intentionality and higher cognitive control of vocalization as well as regions associated with gestures and language. The communication of nonhuman primates was addressed in the previous section in semiotic terms, but without 
considering evidence that nonhuman primates intentionally produce and control their vocalizations, it would be difficult to further speculate about how nonhuman primate models could produce insight into the evolution of language.

It is possible to define Broca's area both by cytoarchitecture ${ }^{2}$ and through gross anatomical markers and review the literature in the area of higher cognitive control of nonhuman primate vocalizations. Broca's area, in modern $H$. sapiens, and in terms of cytoarchitecture is defined as Brodmann's area 44 (pars opercularis) and Brodmann's area 45 (pars triangularis) in the inferior frontal gyrus of the left hemisphere, exhibiting primarily distinctions of Layer III of the cortices with large pyramidal cells for both efferent and afferent connections between somatosensory and motor components (Amunts \& Catani, 2015). Although in modern H. sapiens this area is to some degree specialized for language production, there are functional areas in the premotor cortex and frontal lobes that also influence language production via planning and motor control (Friederici, 2006; Bruner, 2017). There is correlative data that suggests that gross anatomical features vary in both primary (higher cognitive centers) and secondary centers (somatosensory centers) within the boundaries defined through cytoarchitecture (Fischl et al., 2008). Despite this, it seems reasonable that changes to gross anatomy, volume, and relative size, may be used accordingly when working with nonhuman primates both extinct and extant, as well as early hominin endocasts (see Section 4), and in this particular discussion, with areas related to language production.

Although nonhuman primates do not have a Broca's area equivalent in function to that of modern $H$. sapiens, several researchers that have addressed the possibility of the existence of a homologous region (Arbib, 2005). In relation to higher cognitive control and intentionality of vocalizations, there is evidence to suggest that nonhuman primates with behavioral training can produce vocalizations with higher cognitive control in relation to reward-based tasks (Hage, Gavrilov \& Nieder, 2013). Whether or not this is typical of behavior in natural settings is still a topic of further study. However research has demonstrated considerable interaction between auditory processing neurons and those associated with vocal production in the ventrolateral prefrontal cortex, specifically Brodmann's areas 44 and 45, suggesting that these homologs present evidence for the presence of a prefrontal loop that may have served as an evolutionary precursor to basic requirements for speech (Hage \& Neider, 2015). Although homologous regions are still debated, evidence indicating Brodmann's areas 44 and 45 in language production suggests that neuroimaging work displaying increased activity of these functional areas in response to intraspecies communication and vocalizations may provide the groundwork for further exploration (Hage \& Neider, 2015).

In relation to gestural components to language production and acquisition, there is evidence that the F5 area in the premotor monkey cortex (the homologue to Broca's area) functions as a "mirror neuron" system associated with mediating observed actions and performed actions (Arbib, 2005; Zlatev, 2008). Recent neuroimaging has also suggested that Broca's area is active when modern humans both observe and execute grasping action (Arbib, 2005). Gestures and the production of the signed languages of the deaf, which makes use of iconic, indexical, and symbolic signs, is also processed in Broca's area much like

\footnotetext{
${ }^{2}$ Cytoarchitectures are defined by functional areas of the cerebral cortex, and are usually described as having different morphological characteristics related to neuronal populations in the layers of the cortex. Cytoarchitechtures were first described by Brodmann in 1909, and these areas today serve as references for mapping functional brain areas.
} 
spoken language (McNeill, 2005; Bruno, 2012). Considering there is considerable overlap in the neural control of gesturing and language capabilities, it seems likely that language either evolved from bodily mimesis (Donald, 1991; Zlatev, 2008), or that the two co-evolved.

\section{The semiotic capacities of Australopithecus afarensis}

Given the discussion in the previous section, what can we infer about the semiotic capabilities of A. afarensis, a species that lived in Africa 4.2 to 3.0 MYA (Johanson, White, \& Coppens, 1982)? In addition to the findings discussed so far, there is relevant evidence from comparative morphology, in particular from the field of paleoneurology. Because we do not have a live organism to empirically test, careful comparative work of endocasts and fossil specimens that may be used to infer behaviors and biological functions is necessary to be able to draw any conclusions. The current discussion will move from working from overall structure and function from a rudimentary level with cranial capacity, towards a comparison of gross anatomy, cranial morphology and changes to sulci patterns in endocast specimens in relation to functional reorganization, as well as functional systems within the context of higher cognitive and motor processes.

To begin, A. afarensis was bipedal and had an estimated cranial capacity of $440 \mathrm{cc}$ (Neubauer, 2004). In comparison, modern chimpanzees, our closest living relatives as per genetic analysis, have a cranial capacity of 350-400 cc (Sayers, 2012). This does not imply that both species have the same functional capacity, nor does it imply the same cognitive, behavioral or semiotic mechanisms, as volume is not determinate of behavior or function (Holloway, 1966). However, there is evidence to suggest that while brain volume by itself cannot predict cognitive abilities, comparing the composition of neuronal and non-neuronal cells in extant primates and the post mortem tissue of modern $H$. sapiens does indicate a linear cellular scaling effect in the relationship between cranial capacity and body size. This implies that estimates can be made for early hominins given their cranial capacities (Herculano-Houzel \& Kaas, 2011). Although this is a predictive model, it is worthwhile to apply these methods for further analysis, given that if this method can be further applied and tested within the primate order, it may provide an interesting aspect to consider within the context of brain evolution, as well as for predicting body size from incomplete fossil specimens.

Another aspect to consider is what evidence can be gathered about functional regions of the brain associated with language production. This would require a brief discussion of whether or not cranial restructuring toward the human condition began before or after $A$. afarensis. In this context, focusing on cranial restructuring in the frontal lobe is especially relevant. While we have defined Broca's area in regard to cytoarchitecture and by gross anatomical markers in some nonhuman primates, there is evidence to consider from endocasting sources that may better describe the homologous regions in A. afarensis. Beginning again with extant nonhuman primates and modern $H$. sapiens, we may note that gross anatomical markings that are used in defining functional regions in regard to language production in modern $H$. sapiens are typically noted with the extension of portions of the lateral fissure and in extant nonhuman primates that of fronto-orbital sulcus in effect producing a homologue of Broca's area (Falk, 2014). Although A. afarensis was not explicitly examined in this study, other members of this genus were noted to have patterning in this area more like an extant ape than toward the human condition (Falk, 2014). Still, other authors have noted from the literature varying degrees of expansion and reorganization 
within Brodmann's area 44 and 45 homologues in other members of this genus (Carlson et al., 2011; Chase, 2006). The intention here is not to propose that A. afarensis was human-like in cranial structure, but to draw attention to the similarities between what can be inferred about their brains and extant primate cranial morphology.

Consideration of the cortical control of vocalizations (involving Broca's area) involves two other constraints for analysis: auditory processing ranges and the musculature and structures associated with vocal production. According to an analysis of data related to audition in early hominins, austalopithecines (the term used for a number of related species) exhibited a sensitivity to high frequency ranges, thus expanding the range of their audition towards a range more similar to modern H.sapiens (Quam et al., 2015). From this the authors of this study were able to infer that this type of auditory range would be more suited for "short-range intra-group communication" (p. 8) and could be utilized for more than alarm calls or long distance signaling. However, A. afarensis had a vocal tract much more like an ape than modern humans. This suggests that australopithecines produced vocalizations much like modern nonhuman primates, and "lacked the supralaryngeal vocal tract that is necessary for the production of fully encoded human speech" (Lieberman, 1973, p. 59). From this, we can conclude that australopithecines possessed vocalizations indicative of proto-mimesis (see Section 2.2) at the very least. Despite the evidence that some primates make use of indexical signs during vocalizations (Section 3.1), communication between modern primates relies heavily on gesturing (Arbib, Pika, \& Simone, 2008). Such gestures correspond at least to dyadic mimesis, and it can be assumed that australopithecines would have also heavily relied on such gesturing, grounded in iconicity and/or indexicality. There is not enough evidence yet to suggest that australopithecines was capable of the full triadic mimesis, as expressed in e.g. pantomime. What could have been the difference that led first to triadic mimesis, and then to prolific symbol use in H. sapiens? We may turn to mimesis theory to help answer this question.

As stated in Section 2.2. H. sapiens and modern primates are capable of protomimesis, which involves the capacity for "self-other mapping" (Zlatev, 2008). Given the capacities of apes for at least some imitation and gestures, it follows as mentioned that they also exhibit dyadic mimesis. In groups where gesturing is present, those gestures are either "species typical," meaning that these gestures are shared by members of the same species across groups, or they are "idiosyncratic," meaning that they are unique to the individual (Gasser, 2014). However, gesture use varies by site location, implying some degree of conventionalization. This may suggest that there may be a "local gesture culture" and social learning component to gesturing (Gasser, 2014). Again, this would imply that some primates are capable of dyadic mimesis.

Evidence for triadic mimesis is mostly limited to that of humanly encultured primates (Zlatev, 2008). However, there is some (controversial) evidence for both iconic and indexical gesturing by Lowland Gorillas in captivity that were not instructed in human communication (Tanner, 1996). Bonobos have also been suggested to produce both iconic and indexical gesturing (Maestripieri, 2005). Although these behaviors are not noted in natural settings, it is thus possible that some primates do use iconic and indexical gesturing, which would imply that they are capable of triadic mimesis. Beyond this there is evidence that the great apes are even capable of developing a form of protolanguage when given language instruction (Zlatev, 2008). But since the most convincing evidence for degrees of triadic mimesis and postmimesis in extant apes comes in contexts of human enculturation, it seems likely that while apes may have some capacity for these, the firm establishment of this capacity requires the kind of cooperative social structures that is lacking in apes natural habitat (Tomasello, 
2008).

Given the evidence for at least indexical and iconic sign use and mimesis in modern primates and similarities in some of the morphology between apes and australopithecines that was discussed above, it is likely that Australopithecus afarensis was capable of triadic mimesis and thus iconic and indexical gesturing. The question is if they had begun to evolve human-like social cooperation. Given evidence for fairly elaborate Oldowan stone tool technology in this species (Donald, 2013), and this arguably required pedagogy, it is thus possible that the "mimetic revolution" did not occur with Homo ergaster at 1.8 MYA but much earlier.

Another avenue to explore in relation to cognition may be that of the motor abilities and musculature of the upper extremities and hands, as well as the related areas of the motor cortex and premotor regions in australopithecines. As tool production implies volitional control of the body, this skill could have been "exapted" for gesturing as a form of communication along with trend towards short-range vocalizations allowed for meaningful and intentional communication between group members. As to whether or not this produced the first mimetic culture would be an interesting avenue to explore with additional consideration of material culture from the archaeological record.

\section{Conclusions}

This paper explored the use of Peircean semiotics and mimesis theory to address one of the most difficult questions in science: the evolution of human cognition, culture and communication. It was argued on the basis of primatological, neuroanatomical and paleontological evidence that this progressed along a number of stages, with prelinguistic, mimetic communication and cognition, based on indexical and iconic sign use providing a precondition for the evolution of language proper. The australopithecines are an interesting genus in this context because they share characteristics with both extant nonhuman primates and modern $H$. sapiens, and it is possible that their capacities were underestimated in the original mimesis theory (Donald, 1991), while recent research suggests that mimesis in both thought and communication could have been within their grasp.

Further exploration into extralinguistic forms of communication, right hemispheric processing of language, and the integration of other somatosensory systems with that of Broca's area involving both motor processing, auditory processing and the visual pathways may eventually add to the discussion. The argument presented in this paper shows the potential of cognitive semiotics (Zlatev, 2015) to give rise to productive interdisciplinary work combining the Humanities and Natural Sciences.

\section{Acknowledgements}

This paper is the culmination of several years of reading, writing, and editing as I have explored topics related to cognitive-semiotic evolution in hominins, and could not have made possible without the input and editorial work of Professors Jordan Zlatev and Gören Sonesson of the Division for Cognitive Semiotics of Lund University, members of the editorial board from the University of Michigan Undergraduate Journal of Anthropology, and the faculty of the University of Colorado Colorado Springs, Center for Cognitive Archaeology. 


\section{References}

Amunts, K. Catani, M. (2015). Cytoarchitectonics, receptoarchitectonics, and network topology of language. In P. Bandettini, A.W. Toga, P. Thompson, K. Friston (Eds.) Brain Mapping: An Encyclopedia Reference: Acquisition Methods, Methods and Modeling (pp. 177-185). New York, NY: Elsevier.

Arbib, M. A. (2005). From monkey-like action recognition to human language: An evolutionary framework for neurolinguistics. Behavioral and Brain Sciences, 28(02), 105-124.

Arbib, M., Liebal, K., \& Pika, S. (2008). Primate vocalization, gesture, and the evolution of human Language. Current Anthropology, 49(6), 1053-1076.

Bruner, E. (2017). Language, paleoneurology, and the fronto-parietal system. Frontiers in Human Neuroscience, 11, 349.

Karlson, K. J., Stout, D., Jashashvilli, T., De Ruiter, D. J., Tafforeau, P., Carlson, K., \& Berger, L. R. (2011). The endocast of Mh1, Australopithecus sediba. Science, 333(6048), 1402-1407.

Phillip, C. (2006). The Emergence of Culture: The Emergence of a Uniquely Human Way. Philadelphia, PA: Springer.

Clay, Z., \& Zuberbühler, K. (2009). Food-associated calling sequences in bonobos. Animal Behaviour, 77(6), 1387-1396.

Crockford, C., \& Boesch, C. (2005). Call combinations in wild chimpanzees. Behaviour, 142(4), 397-421.

Deacon, T. (1997). The symbolic species. London: Penguin.

Donald, M. (1991). Origins of the modern mind: Three stages in the evolution of human culture. Cambridge, MA: Harvard University Press.

Donald, M. (2013) Mimesis theory re-examined, twenty years after the fact. In Hatfield, G. C. \& Pittman, H. (Eds.) Evolution of mind, brain, and culture, (pp. 169-192). Philadelphia: University of Pennsylvania Museum of Archaeology and Anthropology.

Falk, D. (2014). Interpreting sulci on hominin endocasts: Old hypotheses and new findings. Frontiers in Human Neuroscience, 8, 134.

Fischl, B., Rajendran, N., Busa, E., Augustinack, J., Hinds, O., Yeo, B. T., . . . Zilles, K. (2007). Cortical folding patterns and predicting cytoarchitecture. Cerebral Cortex,18(8), 1973-1980.

Friederici, A. D. (2006). Broca's Area and the Ventral Premotor Cortex in Language: Functional Differentiation and Specificity. Cortex, 42(4), 472-475.

Gasser, B., Cartmill, E. A., \& Arbib, M. A. (2013). Ontogenetic ritualization of primate gesture as a case study in dyadic brain modeling. Neuroinformatics, 12(1), 93-109.

Graham, K. E., Hobaiter, C., Ounsley, J., Furuichi, T., \& Byrne, R. W. (2018). Bonobo and chimpanzee gestures overlap extensively in meaning. PLOS Biology, 16(2), 1-18.

Hage, S. R., \& Nieder, A. (2013). Single neurons in monkey prefrontal cortex encode volitional initiation of vocalizations. Nature Communications, 4(1), 1-11.

Hage, S. R., \& Nieder, A. (2015). Audio-vocal interaction in single neurons of the monkey ventrolateral prefrontal cortex. Journal of Neuroscience, 35(18), 7030-7040.

Hage, S. R., Gavrilov, N., \& Nieder, A. (2013). Cognitive control of distinct vocalizations in rhesus monkeys. Journal of Cognitive Neuroscience, 25(10), 1692-1701. 
Herculano-Houzel, S., \& Kaas, J. H. (2011). Gorilla and orangutan brains conform to the primate cellular scaling rules: Implications for human evolution. Brain, Behavior and Evolution, 77(1), 33-44.

Holloway, J. R. (1966). Cranial capacity, neural reorganization, and hominid evolution: A search for more suitable parameters. American Anthropologist, 68(1), 103-121.

Innis, R. E. (1985). Semiotics: An Introductory Anthology. Advances in Semiotics. Bloomington, IN: Indiana University Press.

Johanson, D. C., White, T. D., \& Coppens, Y. (1982). Dental remains from the Hadar formation, Ethiopia: 1974-1977 collections. American Journal of Physical Anthropology, 57(4), 545-603.

Lieberman, P. (1973). On the evolution of language: A unified view. Cognition, 2(1), 59-94.

Maestripieri, D. (2005). Primate psychology. Cambridge, MA: Harvard University Press.

Matthews, J. (2015). Starting from scratch: The origin and development of expression, representation and symbolism in human and non-human primates, (pp. 1-28). East Sussex: Psychology Press.

Neubauer, S., Mitteroecker, P., Gunz, P., \& Weber, G. (2004). Three-dimensional digital imaging of the partial Australopithecus africanus endocranium Mld 37/38. Journal L'Association Canadienne Des Radiologistes, 55(4), 271-278.

Nöth, W. (1990). Handbook of Semiotics. Advances in Semiotics. Bloomington, IN: Indiana University Press.

Patterson, N., Richter, D. J., Gnerre, S., Lander, E. S., \& Reich, D. (2006). Genetic evidence for complex speciation of humans and chimpanzees. Nature, 441(7097), 1103-8.

Peirce, C. S. (1960). Collected papers of Charles Sanders Pierce (Vol. 8). Cambridge, MA: Belknap Press of Harvard Unversity Press.

Peterson, J. V. (2016). Semiotic communication in nonhuman primates. In S.D. Blum (Ed.) Making Sense of Language: Readings in Culture and Communication, (pp. 37-42). New York, NY: Oxford University Press.

Quam, R., Martinez, I., Rosa, M., Bonmati, A., Lorenzo, C., Ruiter, D. J., . . Arsuaga, J. L. (2015). Early hominin auditory capacities. Science Advances, 1(8), 1-12.

Ouattara, K., Lemasson, A., \& Zuberbuhler, K. (2009a). Campbell's monkeys concatenate vocalizations into context-specific call sequences. Proceedings of the National Academy of Sciences, 106(51), 22026-22031.

Ouattara, K., Lemasson, A., \& Zuberbühler, K. (2009b). Campbell's monkeys use affixation to alter call meaning. PLOS ONE, 4(11), 1-7.

Sapolsky, R. (2006). Social cultures among nonhuman primates. Current Anthropology, 47(4), 641-656.

Sayers, K., Raghanti, M. A., \& Lovejoy, C. O. (2012). Human evolution and the chimpanzee referential doctrine. Annual Review of Anthropology, 41(1), 119-138.

Schenker, N. M., Hopkins, W. D., Spocter, M. A., Garrison, A. R., Stimpson, C. D., Erwin, J. M., . . . Sherwood, C. C. (2010). Broca's area homologue in chimpanzees (Pan Troglodytes): Probabilistic mapping, asymmetry, and comparison to humans. Cerebral Cortex, 20(3), 720-742.

Schlenker, P., Chemla, E., Arnold, K., Lemasson, A., Ouattara, K., Keenan, S., . . . Zuberbühler, K. (2014). Monkey semantics: Two 'dialects' of Campbell's monkey alarm calls. Linguistics and Philosophy, 37(6), 439-501.

Sonesson, G. (2012). The phenomenological road to cognitive semiotics. In G. Enriquez Veloso, P. Couto Cantero, A. Passeri, \& J.M. Paz Gago (Eds.). Culture of Communication/Communication of Culture. Proceedings of the 10th World Congress 
of the International Association of Semiotic Studies, (pp. 855-66). Universidade de Coruña.

Sonesson, G. (2013). The natural history of branching: Approaches to the phenomenology of Firstness, Secondness, and Thirdness. Signs and Society, 1(2), 297-325.

Sonesson, G. (2018). The greatest story ever told: Semiosis emerging from mimesis and/or narrativity. Proceedings of the 12th International Conference on the Evolution of Language (Evolang12).

Tanner, J. E. Byrne, R. W. (1996). Representation of action through iconic gesture in a captive lowland gorilla. Current Anthropology 37(1), 162-73.

Zlatev, J. (2002). Mimesis: The "missing link" between signals and symbols in phylogeny and ontogeny. In A. Pajunen (Ed.). Mimesis, Sign and the Evolution of Language, (pp. 93-122). Turku: University of Turku Press.

Zlatev, J. (2005). What's in a schema? Bodily mimesis and the grounding of language. In. Hampe, B. (Ed.) From Perception to Meaning Image Schemas in Cognitive Linguistics (pp. 313-342). Berlin: Mouton de Gruyter.

Zlatev, J. (2008). From proto-mimesis to language: Evidence from primatology and social neuroscience. Journal of Physiology-Paris, 102(1-3), 137-151.

\section{Author Address}

University of Pittsburgh, Department of Communication Sciences and Disorders, Bridgeside

Point, Suite 301, 100 Technology Drive, Pittsburgh, PA, 15219.

Email: jem315@pitt.edu

\section{About the Author}

Jenny Michlich is an undergraduate at the University of Pittsburgh studying Anthropology, the History and Philosophy of Science, and Neuroscience. She is also attending the University of Colorado Colorado Springs Extended Studies Program completing an undergraduate certificate in Cognitive Archaeology. Jenny has an interest in cognitive evolution, speech, and language evolution, approached from perspectives in cognitive semiotics, evolutionary anthropology and neuroscience. She currently holds a position as a Research Assistant at Magee-Womens Research Institute and Foundation, as well as a Research Assistant position in the Helou Laboratory for Vocal Systems Anatomy and Physiology Research at the University of Pittsburgh, Department of Communication Sciences and Disorder, headed by Professor Leah B. Helou. 